\title{
Adoption of mobile social media for learning among Chinese older adults in senior citizen colleges
}

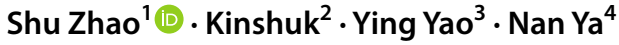

Accepted: 15 September 2021 / Published online: 27 September 2021

(c) Association for Educational Communications and Technology 2021

\begin{abstract}
Mobile social media are increasingly being used in education. They provide an effective way to address the imbalance between teaching supply and demand for older adults. However, few studies have investigated which factors contribute to older adults' intention to use mobile social media for learning. This study uses a sequential explanatory mixed method to investigate the factors impacting older Chinese adults' adoption of mobile social media for learning. Results of the quantitative phase indicated that Technology Anxiety (TA), Self-efficacy (SE), Previous Experience (PE), and Subjective Norm (SN) had significant effects on Perceived Usefulness (PU). TA, SE, PE, and Facilitating Conditions (FC) had significant effects on Perceived Ease of Use (PEU). PU and PEU are significant predictors of Behavioral Intention (BI), and PEU had a positive effect on PU. In the qualitative study, the significant effects of these extension factors on PU and/or PEU were investigated further. Perceptions and concerns about using mobile social media for learning were analyzed based on the participants' interview data. On the basis of these results, recommendations are made to promote the use of mobile social media for learning by older adults. Specifically, teachers and colleges should: (a) select appropriate social media applications and set up relevant courses, and (b) supply inexpensive network service and high-quality learning support service. These research results have important implications for academic researchers, senior college managers, and teachers.
\end{abstract}

Keywords Technology acceptance model $\cdot$ Mobile social media $\cdot$ Mobile learning $\cdot$ Older adult education

\section{Introduction}

Mobile learning (m-learning) has become a significant trend in education (Wu et al., 2012), and many applications are currently being developed to support m-learning. Among these applications, mobile social media applications have proven to be an effective means for improving students' educational interaction and collaboration (Gikas \& Grant, 2013). Utilizing the Internet and Web 2.0 technologies, social media apps allow users to create and

Shu Zhao

zhaoshu@snnu.edu.cn

Extended author information available on the last page of the article 
exchange content and participate in various virtual communities through functions such as chatting, sharing, collaborating, publishing, and interacting.

In China, mobile social media applications have become immensely popular in the daily life and education of senior citizens. There are about 96 million active elderly users of mobile social media (Qutoutiao, 2020). Four main kinds of social media applications are used among older Chinese adults: instant messaging applications (e.g., WeChat, QQ); news and information sharing applications (e.g., Toutiao); photo or video-sharing applications (e.g., TikTok), and other comprehensive social media applications (e.g., Weibo). Among these applications, WeChat has become the most popular social media app among older Chinese people, and about $90 \%$ of older people have either heard of or used WeChat (Zhang, 2019). These older Chinese people use the WeChat app to maintain interpersonal communication, get and share knowledge, and pay daily bills. There were over 61 million older WeChat users in 2018. The number of older mobile internet users has increased annually since 2012 (Tencent Technology Company, 2018).

Using mobile social media is an effective way to reach large numbers of older people and maintain a balance between teaching supply and demand among older adults (General Office of the State Council, 2016). The growth of China's aging population is accelerating (Liu et al., 2018). The demand for learning opportunities for the elderly after retirement is also increasing (Findsen \& Formosa, 2012). However, by the end of 2015, only 7 million elderly people have been able to attend senior citizen colleges out of the 2.2 billion elderly people in China (Yang \& Ouyang, 2018). Senior citizen colleges have become so popular that older adults have started waiting in line overnight just to secure a coveted spot, especially for popular classes such as piano and English.

Although the use of social media for learning is popular and important, little research has been performed on older adults' interest in m-learning using social media (Chen \& Chan, 2011). Understanding older adults' behavior toward and interest in this new learning style can help academic researchers, senior college managers, and teachers to create mechanisms for encouraging older adults to adopt it. Therefore, research on older learners' attitudes and intentions to use m-learning is important. This is particularly important in the Chinese context, considering China's rapidly aging population.

\section{Literature review and research questions}

Kaplan and Haenlein (2010) define social media as "a group of Internet based applications that build on the ideological and technological foundations of Web 2.0, and that allow the creation and exchange of user generated content". Research on the use of social media by the elderly is growing (Chou et al., 2013; Goswami et al., 2010). However, few studies have focused on older adults' adoption of social media for m-learning, and fewer still have focused on older Chinese adults.

\section{Older adults' adoption of social media for m-learning}

According to the existing literature, many factors may influence older adults' acceptance of, and behavioral intentions toward, technology (Chen \& Chan, 2011). These factors can be divided into three main contexts: the individual, the social, and the organizational (Park et al., 2012). 
The individual context consists of factors related to an older adult's physical and psychological decline with age. For example, previous experience (PE) is an important factor that affects older adults' behavior (Chen \& Chan, 2014). Compared to younger people, older adults are more resistant to change and more cautious before they act. If they have positive PE with using technology, then they will be encouraged to try new innovations like social media. Technology anxiety (TA) is another important factor. As older people usually have less experience with mobile technology, they tend to have higher levels of TA (Dyck et al., 1998). Some studies have found a significant relationship between anxiety and self-efficacy (SE) (Bandura, 1988; Razavi et al., 2017; Saadé \& Kira, 2009). These factors may have a special meaning in the Chinese context. Many older Chinese adults have lower SE compared to younger adults. One reason for this is the older adults' physical and psychological decline. Another important reason is that the Chinese culture of modesty may lead to low SE (Salili et al., 2001).

The social context consists of social influences on an individual's acceptance of using social media for m-learning. Subjective Norm (SN), for example, influences people's willingness to adopt new technology (Venkatesh et al., 2003). SN is defined as the degree to which an individual perceives that people who are important to him/her think he/she should or should not use the system (Venkatesh \& Davis, 2000). It is a crucial factor in shaping elderly people's intentions (Lu, 2012). Compared to Americans or Europeans, Chinese people tend to assign more significance to the expectations and views of persons or groups who are important to them (Yang \& Ouyang, 2018).

The organizational context consists of any organization's influence on or support for one's m-learning. Facilitating Condition (FC) is one such organizational factor impacting m-learning behavior (Althunibat, 2015; Hao et al., 2017). Facilitating conditions refer to the degree to which an individual believes an organizational and technical infrastructure will support his or her use of the system. This factor also influences older people's adoption of technology (Mallenius et al., 2007; Steele et al., 2009). Compared to younger learners, older adult learners may need more support during their m-learning process. For older Chinese people, it is particularly important that FC should include learning costs. In China, the social security system is not very strong. Statistics show that $61.2 \%$ of Chinese seniors worry that their pensions are not sufficient (China Youth Daily, 2016). Older Chinese adults may, therefore, have more concern about learning costs.

Previous studies have found that many factors influence older adults' behaviors. However, little research has focused on the specific context of mobile social media, and existing research has rarely considered the three factors of individual, social, and organizational context. In light of the above research and the actual situation of the elderly in China, we chose to focus on five factors: technology anxiety (TA), self-efficacy (SE), previous experience (PE), subjective norm (SN), and facilitating conditions (FC). These factors are discussed further in the next section.

\section{Social media for m-learning among older Chinese adults}

In China, m-learning applications are widely used in adult education, but the usage mode is different than that found in K-12. In Chinese adult education, m-learning is flexible. In class, students can use mobile applications to interact with teachers or peers and submit their assignments. After class, they can review learning materials and submit homework with their mobile phones. In 2020, as a result of the COVID-19 pandemic, distance 
m-learning has become the dominant delivery mode for the education of older adults in China.

The usefulness of mobile social media applications has led to their wide use as m-learning tools in education, particularly for the Chinese elderly (Fu, 2019). Taking WeChat as an example, social features such as text/video/picture messaging, interest-based groups, and information search and sharing are all used in m-learning among older adults. In the context of m-learning via social media, elderly learners can choose their learning medium and communication tools (Leen \& Lang, 2013). While self-directedness and freedom of m-learning are appealing for any age group, they are particularly important to older adults because they only sporadically have time available from their everyday chores and childcare. Using social media for m-learning could also help deal with social isolation. In China, retirement and the trend towards dissolution of the traditional family have led older adults to spend more time on social media. In addition to using social media for communicating with others, they tend to use it to learn information related to their interests and health. In some senior citizen colleges in China, a few teachers have started to organize teaching and learning activities through WeChat.

To sum up, although m-learning through social media is significant to Chinese seniors, little is known about what factors influence older Chinese adults' adoption of mobile social media, and how older Chinese adults use these tools for learning in addition to their daily uses for entertainment and communication. Therefore, this study investigated the following research questions: What factors influence older Chinese adults' adoption of mobile social media for learning? What are the current experiences, perceptions, and challenges of using mobile social media for learning among older adults in senior citizen colleges in China?

To answer the first research question, an extended technology acceptance model (TAM) is proposed. This model is based on that of Park (2012) and has been modified to be suitable for use with older Chinese adults. To confirm the accuracy of the extended TAM and to answer the second research question, a qualitative research investigation was carried out as well. In the following sections, we describe the proposed research model and methodology, present analytical results, and discuss the implications and conclusions of this study.

\section{Theoretical framework}

The technology acceptance model (TAM) is considered to be a robust tool for measuring the adoption of new technology. TAM is in common use and has received extensive empirical support in many educational studies (Scherer et al., 2019). Originating in the psychological theory of reasoned action and the theory of planned behavior, the technology acceptance model (TAM) was first proposed by Davis (1986). The model suggests that when users are presented with technology, two core factors- perceived usefulness (PU) and perceived ease of use (PEU)-influence their attitude toward adoption; this attitude is the most influential antecedent of actual system use. By adding external variables to the original model, many extended TAMs have been proposed in the literature (Park et al., 2012; Venkatesh \& Davis, 2000; Venkatesh et al., 2003). Existing studies verify the effectiveness of TAM-based approaches that have been used to analyze the adoption of information communication technologies (ICTs) by the elderly (Chen \& Chan, 2011).

In order to verify older Chinese adults' adoption of social media for m-learning, this research proposed a research model based on TAM and on Park's model (2012). In Park's model, the variables related to the adoption of m-learning are divided into three 
contexts: the individual, the social, and the organizational. We adjusted Park's model to take into account the differences between older adults and traditional college students. External factors, major relevance, and system accessibility were deleted because, according to the literature, they are not relevant to older adults. Three external factors, namely PE, TA, and FC, were added to the research model in light of their importance in affecting the behavior of older adults (Chen \& Chan, 2014; Deng et al., 2014; Mallenius et al., 2007). In addition, considering the weak mediating role of attitude between the two perceived beliefs (PU and PEU) and behavioral intention (BI,) Venkatesh and Davis (2000) modified TAM by eliminating attitude. The modified TAM has been extensively tested (Lee \& Lehto, 2013). Therefore, the modified TAM was adopted for this study. The final proposed research model is summarized in Fig. 1.

Based on the above research model, the following hypotheses are proposed:

H1 PU has a positive effect on BI.

H2a PEU has a positive effect on BI.

H2b PEU has a positive effect on PU.

H3a Mobile TA has a negative effect on PU.

H3b Mobile TA has a negative effect on PEU.

H4a SE has a positive effect on PU.

H4b SE has a positive effect on PEU.

H5a PE has a positive effect on PU.

H5b PE has a positive effect on PEU.

H6a SN has a positive effect on PU.

H6b SN has a positive effect on PEU.

H7a FC has a positive effect on PU.

H7b FC has a positive effect on PEU.

\section{Methods}

This study adopted a sequential explanatory mixed method, which integrates qualitative and quantitative methods during the interpretation phase (Creswell, 2003). Quantitative and qualitative data were collected in turn via questionnaires and interviews. To answer the first research question, an extended technology acceptance model (TAM) was proposed and verified based on the questionnaires. The interview data related to the five 


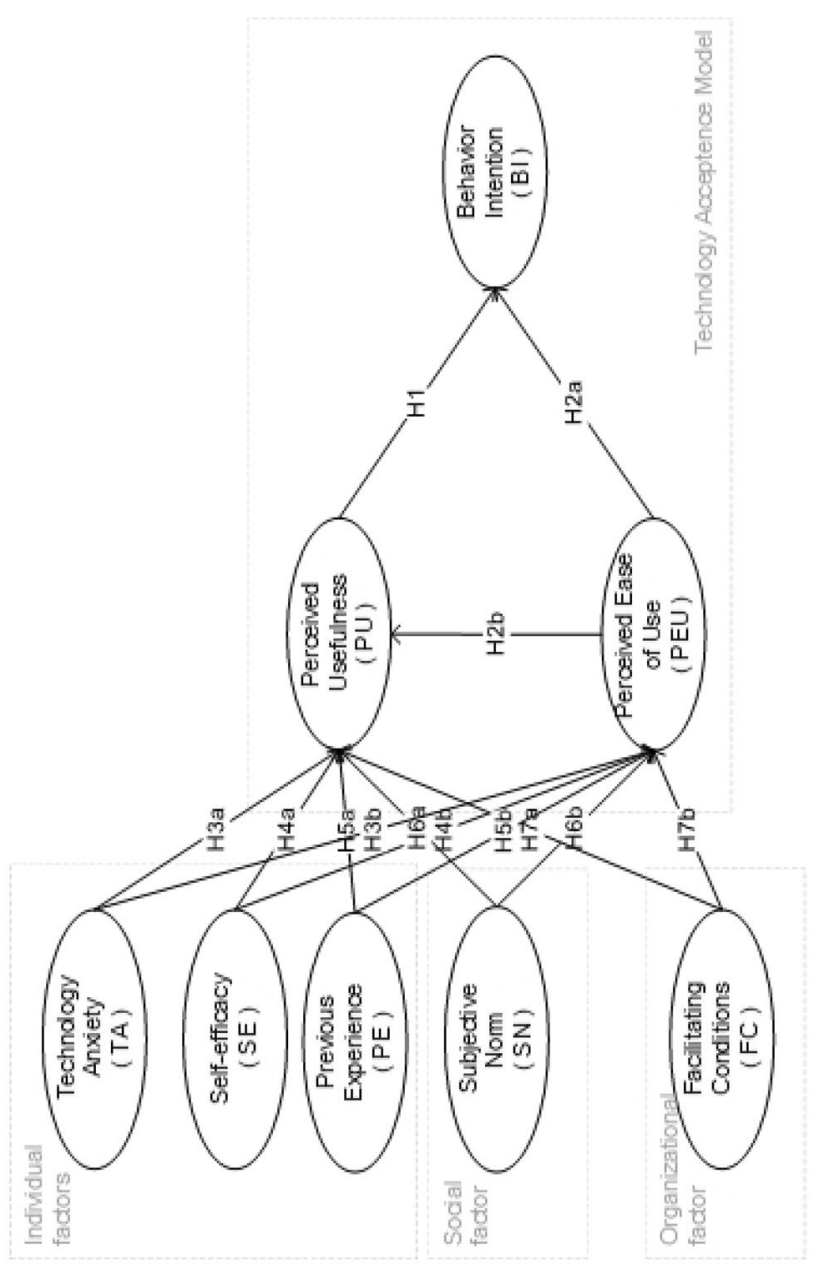

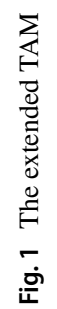


factors were also analyzed to better understand the participants' detailed reasoning and stories behind their questionnaire responses. To answer the second question, the qualitative data from interviews were analyzed and three themes were identified.

\section{Participants}

Quantitative and qualitative data were collected in mainland China; the main sample was drawn from the students of three senior citizen colleges. 484 participants (aged 50 and older) from three senior citizen colleges finished the questionnaires. 17 participants (6 males and 11 females) who completed the questionnaires volunteered to participate in the interview. All the participants were 50 years old or older. Although most developed countries have accepted the chronological age of 65 years as a definition of "elderly," this definition does not apply well to the situation in China. The mandatory retirement age in China is currently 60 for men, 55 for white-collar women, and 50 for blue-collar women; in 1978, the Chinese government set different retirement ages for men and women to protect the interests of women because women were subject to the strain of bearing and rearing children. Although there are no explicit provisions against working beyond the retirement age in China, Chinese traditional culture and mandatory retirement policies reduce the possibility of working beyond the retirement age. Senior citizen colleges have therefore become a popular way for older adults to spend their spare time. The admission age in most senior colleges is 50 and above. Therefore, we set the age for survey participation as 50 or more. Most of the respondents had smartphones with social media applications installed, such as WeChat, QQ, TikTok, or other video sharing applications.

\section{Instruments}

The questionnaire used in this study consists of two parts: one regarding demographic information, and one for technology acceptance. Demographic information includes the participants' age, gender, education level, and past experience in using social media for m-learning. Technology acceptance includes eight constructs (see Fig. 1). Items for each construct in this study were developed based on prior studies, to ensure the content validity of all items. These items had sufficient flexibility to be slightly adapted and modified to suit the context of older adults' m-learning. To verify content validity, the questionnaire was submitted to four experts, including two English teachers from a traditional college and two subject teachers from a senior citizen college. The English teachers were asked to evaluate the consistency of the English-Chinese translation and its comprehensibility, while the teachers from the senior citizen college were asked to comment on the questionnaire's length, format, and comprehensibility. The final questionnaire included 8 constructs and 25 measurement items (see Appendix Table 10). All measurement items were measured on a 5-point Likert scale ranging from $1=$ strongly disagree to $5=$ strongly agree.

To further verify and analyze the quantitative results and to gain insight into the older adults' perceptions of the use of mobile social media for learning, semi-structured interview questions were developed. The five constructs of the research model were explained to the participants first. Then all interviews were initiated with the following questions: Did the five constructs influence you to use mobile social media for learning, and if so, how? 
What's your current experience with the use of mobile social media? What's your opinion about using social media for learning? What difficulties or problems do you encounter when using social media for m-learning? The participants gave permission for the interviews to be audiotaped by a voice recording app for later analysis by team members.

\section{Procedure}

First, the questionnaires were distributed by investigators to the respondents in a faceto-face setting to ensure the quality and accuracy of the results. Before the respondents completed the questionnaires, the investigators explained the concept of social media and common applications (WeChat, QQ, TikTok, etc.). The respondents had the right to withdraw from the study while answering the questionnaires. To maintain consistency with ethics and the criteria of privacy in research, the respondents were told that the confidentiality of their information was strictly ensured. Data collected through the questionnaires were analyzed by Structural Equation Modeling (SEM) using the maximum likelihood method. As suggested by Anderson and Gerbing (1988), a twostep modeling approach, including the measurement model and the structural model, was used. First, Cronbach's alpha and confirmatory factor analysis (CFA) were used to test the measurement model. SPSS 21.0 software was used to evaluate the descriptive statistics and Cronbach's alpha coefficients. Then, regression analysis was used to estimate the proposed structural model. The relationships in the structural model were estimated using AMOS 22.0.

Second, focus group interviews lasting 35 and 40 min were conducted with the volunteers. The two focus groups were composed of eight and nine older adults who were asked to answer semi-structured interview questions. Their answers were audiotaped. The interview data were analyzed by two researchers following four steps: (a) transcribing the interview data; (b) repeatedly reading the data to gain a deep understanding of it; (c) coding the data; and (d) interpreting the data (Ruona, 2005). To establish the reliability of the qualitative data analysis, the procedures proposed by Creswell and Clark (2007) were used. Two researchers defined the nodes based on the theoretical framework of the extended TAM and the interview themes. After interview data were transcribed, they read the transcripts individually. Then they worked together to discuss emerging themes arising from the data, refine the nodes, and finally devised a code list. After that, they both coded the same interview transcript individually. They then met and checked their work for internal consistency. The value of Cohen's Kappa coefficient for the analysis was 0.801 . Using the code list, each researcher analyzed half of the rest of the interviews. Nvivo 12 was used to analyze interviews. Eight major coding themes (TA, SE, PE, SN, FC, mobile social media preference; perceptions of social media for m-learning; concerns about using social media for m-learning) were identified. 


\section{Results}

\section{Research question 1: Factors influencing older Chinese adults' adoption of mobile social media for learning}

The quantitative data confirmed that the enumerated factors do indeed influence older Chinese adults' adoption of mobile social media for learning. The qualitative data further verified and enriched the quantitative data by providing supporting examples, explanations, and anecdotes.

\section{Demographic characteristics}

In this study, 484 questionnaires were distributed and 391 returned questionnaires were found to be valid for analysis. The demographic results are shown in Table 1. Most respondents (84.4\%) were between the ages of 50 and 59 , and only $1.8 \%$ of the respondents were older than 64 . The respondents' education level was generally high. Although only $24.3 \%$ of respondents had received a college education, this level was still higher than that for the population as a whole, according to the report of the National Bureau of Statistics of the People's Republic of China (2010). In addition, $86.2 \%$ of the respondents had had the experience of using mobile social media for more than one year. The statistics showed that the sex ratio of female to male was about $4: 1$, indicating a significant gender imbalance which reflects the gender imbalance of students studying at senior citizen colleges in China. This difference may be related to the different retirement ages for the two genders.

Table 1 Demographics of respondents $(\mathrm{N}=391)$

\begin{tabular}{llc}
\hline Category & Frequency & Percent $(\%)$ \\
\hline Age & & \\
50-54 years old & 105 & 26.9 \\
55-59 years old & 225 & 57.5 \\
60-64 years old & 54 & 13.8 \\
Over 64 years old & 7 & 1.8 \\
Gender & & \\
Male & 73 & 18.7 \\
Female & 318 & 81.3 \\
Education level & & \\
Elementary school and below & 23 & 5.9 \\
Middle school education & 273 & 69.8 \\
Bachelor's degree & 92 & 23.5 \\
Master's degree & 3 & 0.8 \\
Past experience of using mobile social media applications \\
Less than one year & 54 & 13.8 \\
One to two years & 151 & 38.6 \\
Two to three years & 92 & 23.5 \\
More than three years & 94 & 24.0 \\
\hline
\end{tabular}


Table 2 Reliability and convergent validity

\begin{tabular}{|c|c|c|c|c|c|}
\hline Constructs & Items & Cronbach's alpha & Factor loadings & $\mathrm{CR}$ & AVE \\
\hline \multirow[t]{3}{*}{$\mathrm{TA}$} & TA1 & 0.77 & 0.87 & 0.77 & 0.54 \\
\hline & TA2 & & 0.66 & & \\
\hline & TA3 & & 0.65 & & \\
\hline \multirow[t]{3}{*}{ SE } & SE1 & 0.85 & 0.74 & 0.86 & 0.67 \\
\hline & SE2 & & 0.73 & & \\
\hline & SE3 & & 0.97 & & \\
\hline \multirow[t]{3}{*}{ PE } & PE1 & 0.83 & 0.72 & 0.85 & 0.66 \\
\hline & PE2 & & 0.99 & & \\
\hline & PE3 & & 0.69 & & \\
\hline \multirow[t]{3}{*}{$\mathrm{SN}$} & SN1 & 0.88 & 0.78 & 0.88 & 0.72 \\
\hline & $\mathrm{SN} 2$ & & 0.80 & & \\
\hline & $\mathrm{SN} 3$ & & 0.95 & & \\
\hline \multirow[t]{4}{*}{$\mathrm{FC}$} & FC1 & 0.87 & 0.72 & 0.88 & 0.64 \\
\hline & $\mathrm{FC} 2$ & & 0.74 & & \\
\hline & $\mathrm{FC} 3$ & & 0.99 & & \\
\hline & $\mathrm{FC} 4$ & & 0.73 & & \\
\hline \multirow[t]{3}{*}{$\mathrm{PU}$} & PU1 & 0.83 & 0.70 & 0.83 & 0.63 \\
\hline & PU2 & & 0.73 & & \\
\hline & PU3 & & 0.93 & & \\
\hline \multirow[t]{3}{*}{ PEU } & PEU1 & 0.85 & 0.97 & 0.85 & 0.67 \\
\hline & PEU2 & & 0.73 & & \\
\hline & PEU3 & & 0.74 & & \\
\hline \multirow[t]{3}{*}{ BI } & BI1 & 0.82 & 0.96 & 0.84 & 0.63 \\
\hline & $\mathrm{BI} 2$ & & 0.68 & & \\
\hline & $\mathrm{BI} 3$ & & 0.72 & & \\
\hline
\end{tabular}

\section{Measurement model}

In the first step of modeling, confirmatory factor analysis (CFA) was used to test whether the data fit the hypothesized measurement model. Construct reliability and convergent and discriminant validity were initially tested (Chow et al., 2012). Construct reliability was

Table 3 Correlation matrix and discriminant validity

\begin{tabular}{lcccccccc}
\hline & FC & SE & SN & TA & PE & PEU & PU & BI \\
\hline FC & 0.800 & & & & & & & \\
SE & 0.431 & 0.819 & & & & & & \\
SN & 0.548 & 0.469 & 0.849 & & & & & \\
TA & -0.441 & -0.411 & -0.553 & 0.735 & & & & \\
PE & 0.416 & 0.424 & 0.434 & -0.289 & 0.812 & & & \\
PEU & 0.442 & 0.464 & 0.419 & -0.420 & 0.434 & 0.819 & & \\
PU & 0.464 & 0.521 & 0.513 & -0.456 & 0.435 & 0.470 & 0.794 & \\
BI & 0.269 & 0.293 & 0.277 & -0.260 & 0.258 & 0.432 & 0.440 & 0.794 \\
\hline
\end{tabular}


Table 4 Model fit indices

\begin{tabular}{llll}
\hline Fit indices & Value & Level of acceptable fit & Results \\
\hline $\mathrm{X}^{2} / \mathrm{df}$ & 1.105 & $<3($ Kline, 2005$)$ & Good \\
CFI & 0.995 & $>0.9($ Kline, 2005$)$ & Good \\
GFI & 0.948 & $>0.9($ Kline, 2005$)$ & Good \\
AGFI & 0.933 & $>0.9($ Kline, 2005$)$ & Good \\
RMSEA & 0.016 & $<0.08($ Byrne, 2016) & Good \\
\hline
\end{tabular}

CFI Comparative fit index, GFI Goodness of fit index, AGFI Adjusted goodness of fit index, RMSEA Root mean square error of approximation

Table 5 Hypothesized relationships

\begin{tabular}{|c|c|c|c|}
\hline Casual path & $\begin{array}{l}\text { Standardized } \\
\text { coefficients }\end{array}$ & $p$ & Supported \\
\hline 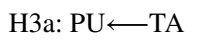 & -0.131 & .037 & Yes \\
\hline H3b: PEU —TA & -0.178 & .006 & Yes \\
\hline H4a: PUせSE & 0.228 & $<.001$ & Yes \\
\hline H4b: PEU & 0.214 & $<.001$ & Yes \\
\hline H5a: PUせPE & 0.125 & .017 & Yes \\
\hline H5b: PEU —PE & 0.206 & $<.001$ & Yes \\
\hline H6a: PU־SN & 0.162 & .011 & Yes \\
\hline H6b: PEU & 0.042 & .514 & No \\
\hline H7a: PU $\longleftarrow$ FC & 0.105 & .060 & No \\
\hline H7b: PEU —FC & 0.162 & .005 & Yes \\
\hline $\mathrm{H} 1: \mathrm{BI} \longleftarrow \mathrm{PU}$ & 0.304 & $<.001$ & Yes \\
\hline $\mathrm{H} 2 \mathrm{a}: \mathrm{BI} \longleftarrow \mathrm{PEU}$ & 0.289 & $<.001$ & Yes \\
\hline $\mathrm{H} 2 \mathrm{~b}: \mathrm{PU} \longleftarrow \mathrm{PEU}$ & 0.140 & .013 & Yes \\
\hline
\end{tabular}

tested through Cronbach's $\alpha(>0.7)$, and through composite reliability (CR $>0.7)$ (Nunnally \& Bernstein, 1994; Yang \& Wang, 2019). Convergent validity was tested by the values of factor loadings $(>0.5)$, composite reliability $(C R>0.7)$, and average variance extracted (AVE > 0.5) (Byrne, 2016; Hair et al., 2009). Cronbach's $\alpha$ was calculated by SPSS 21.0. CR and AVE were calculated by the CR and AVE formulas given by Fornell and Larcker (1981). Table 2 lists Cronbach's alpha, factor loadings, CR, and AVE for the various constructs. The scores of each construct were higher than the acceptability criterion, suggesting adequate construct reliability and validity.

To verify discriminant validity, the square roots of each construct's AVE should be greater than the correlations with other latent constructs (Fornell \& Larcker, 1981). As shown in Table 3, the values of the square roots of each construct's AVE are all higher than the correlations between the constructs, suggesting acceptable discriminant validity. In summary, the reliability and validity of the constructs in the measurement model are adequate. 


\section{Structural model}

As the second step of modeling, the fit indices of the structural model were estimated by using AMOS 22.0. As shown in Table 4, the model fit indices were within the desirable range of values suggested by the literature, indicating a good fit between the structural model and the data.

The maximum likelihood method was used to test the hypotheses in the structural model. The results are shown in Table 5. All path coefficients were verified to be statistically significant, except $\mathrm{H} 6 \mathrm{~b}$ and $\mathrm{H} 7 \mathrm{a}$. These results were in agreement with the research results of TAM3 (Venkatesh \& Bala, 2008). SN was one of the predictors of PU. FC had significant effects on PEU. The results of SN in this stage were different from that in the stage of the interview data; this fact will be discussed later in the following section.

\section{Factors influencing the adoption of social media for m-learning}

For the interviews, five themes were identified based on the theoretical framework. Each theme dimension was coded with a valence (i.e., " + " or "-") to denote whether the dimension seemed to have a positive effect on the older adults' adoption behavior $(+)$ or, seemed to have a negative effect on the older adults' adoption behavior (-). The frequency counts are provided in Table 6. It was determined that the participants expressed views about "FC" 36 times; views about "TA" 29 times; and views about "SN" 21 times. The result is approximately consistent with the findings of the quantitative research phase except for hypothesis H6b. In the quantitative study, the data presented SN as having a positive influence on PU, but not PEU. But in the qualitative study, SN was found to have a positive influence on both PU and PEU. There are two possible explanations for this result. First, the results may relate to the way in which the items were written (Appendix Table 10). Although these items were developed based on

Table 6 Five constructs frequency counts

\begin{tabular}{clc}
\hline Constructs & $\mathrm{f}_{\text {participant }}$ & $\mathrm{f}_{\text {code }}$ \\
\hline $\mathrm{TA}$ & 1 & \\
+ & 1 & 2 \\
- & 12 & 27 \\
$\mathrm{SE}$ & & \\
+ & 7 & 11 \\
- & 2 & 2 \\
$\mathrm{PE}$ & & \\
+ & 9 & 11 \\
- & 2 & 3 \\
$\mathrm{SN}$ & & \\
+ & 10 & 17 \\
- & 2 & 4 \\
$\mathrm{FC}$ & & 34 \\
+ & 13 & 2 \\
- & 1 & \\
\hline
\end{tabular}




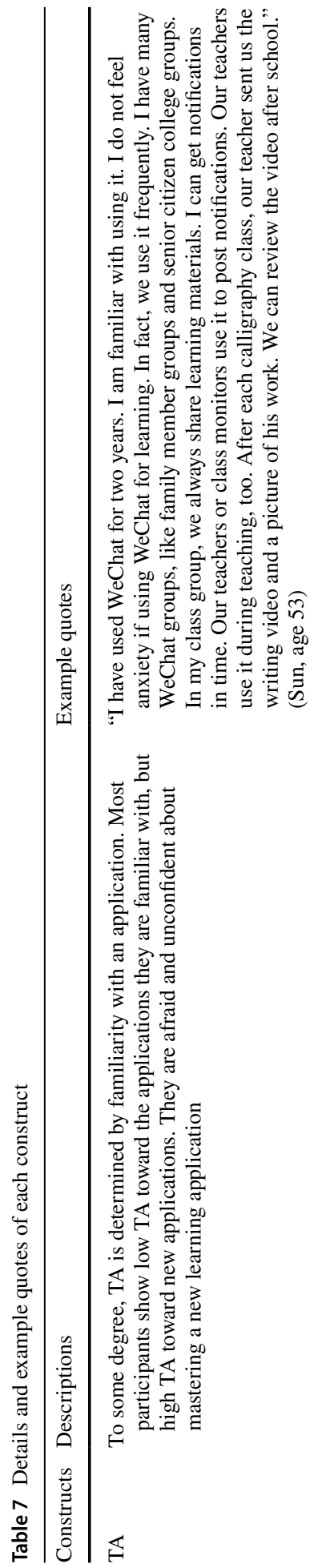

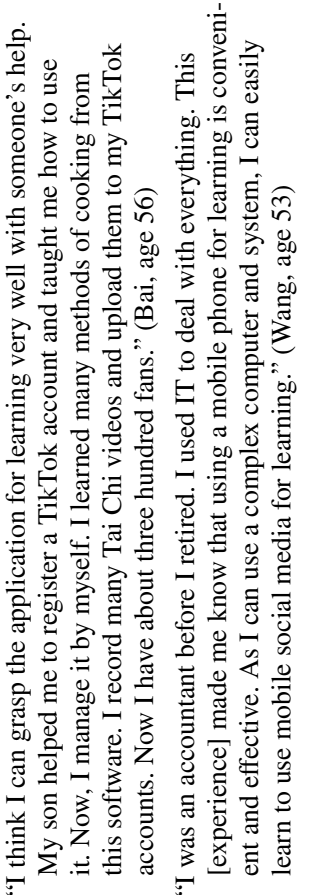

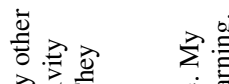
ठิ.

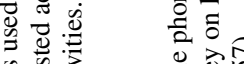

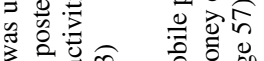

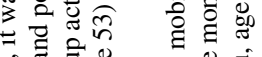

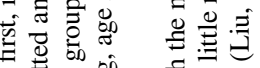
要

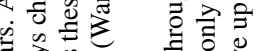

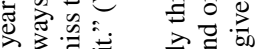
元

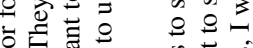
ये⿺ के है

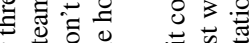

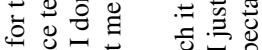

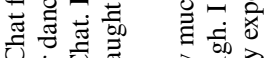

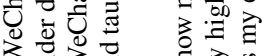

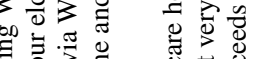

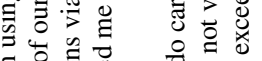

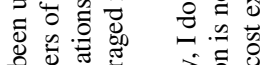

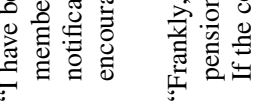

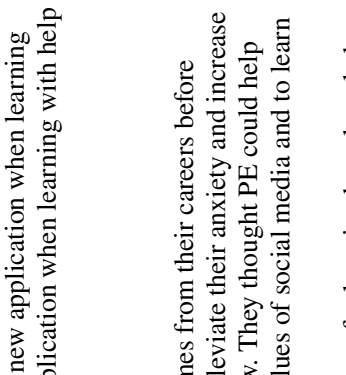

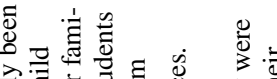

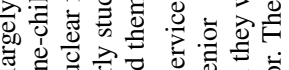

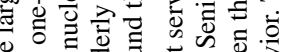

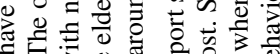
on

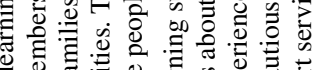

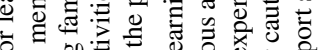

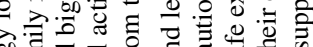

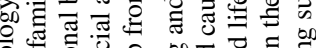
๘ 至

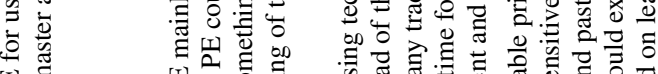

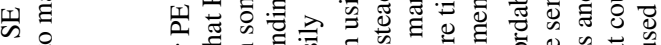

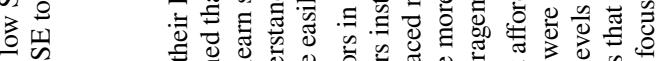

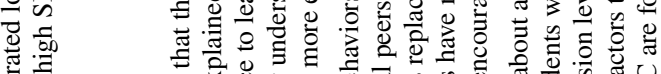

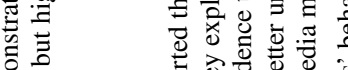

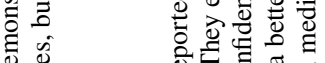

प)

苛泀

อ 넌 में 过 0 क

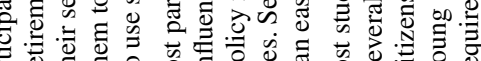

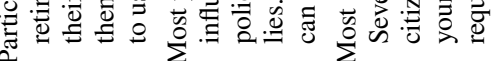

떤

닌

Z

诖 
previous studies, the items for SN overall tended to focus on PU and not PEU. Second, as an individual's perception, $\mathrm{SN}$ is expressed emotionally in the interview stage.

In addition to confirming the hypotheses of the quantitative research, the interview data also described in detail the influence of each construct, as shown in Table 7.

\section{Research question 2: Current experiences, perceptions, and concerns about using mobile social media for learning among older adults}

Seventeen older adults from senior citizen colleges were divided into two focus groups, and their views were analyzed. According to the analysis of the transcripts, three major themes were identified from the participants' comments (i) mobile social media preferences; (ii) perceptions of social media for m-learning; (iii) concerns about using social media for m-learning.

\section{Mobile social media preferences}

According to the interview data, four mobile social media apps were frequently mentioned as being used. Table 8 shows the frequency counts of preferences for social media. Students expressed that they like to use WeChat to communicate with each other and to share digital courses. Some students like to share their works of calligraphy or photography. Toutiao, as a news and information sharing app, is widely used by the students to obtain and discuss information related to their interests. On the TikTok platform, there are many short videos about health maintenance and Chinese opera that are of interest to older adults. 8 participants had TikTok accounts and had posted videos.

\section{Perceptions of social media for m-learning}

In general, the older adults showed positive attitudes towards the use of social media for m-learning even though they sometimes found the technology difficult to use. Two concepts were identified from the participants' comments: learning materials and learning strategies.

The participants felt that they can obtain abundant learning materials through social media. They believed that these learning materials are useful (mentioned 18 times), interesting (16), interactive (11), and creative (11). For example, one male student stated that he was accustomed to browsing the news daily through the Toutiao app. As the list of contents in the Toutiao app is generated based on the users' interaction with content, the older people can thereby obtain information related to their interests and learning themes.

Table 8 Frequency counts of preferences for social media

\begin{tabular}{lll}
\hline Mobile social media & $\mathrm{f}_{\text {participant }}$ & $\mathrm{f}_{\text {code }}$ \\
\hline WeChat & 17 & 42 \\
Toutiao & 13 & 25 \\
TikTok & 11 & 14 \\
Weibo & 7 & 9 \\
\hline
\end{tabular}


The participants expressed the belief that social media tools provided good learning strategies. For example, they stated that social media were convenient for reviewing learning materials (mentioned 22 times), helped one connect with other students or friends (15), provided an effective way to share assignments (12), and provided interactive learning support (12).

\section{Concerns about using social media for m-learning}

The interview data indicated that while a few participants had no concerns about using mobile social media, most of them voiced concerns focused on cybersecurity, technical difficulties, and non-technical difficulties. Their cybersecurity concerns include Internet fraud (mentioned 28 times), online privacy (17), online payment safety (13), and computer viruses (8). Their concerns over technical difficulties include problems with software operation (17), mobile device operation (13), network connections (13), and software services (10). Their concerns about non-technical difficulties include information disorientation (17) and information overload (15). These factors can affect older adults' adoption of social media to some extent. Some older adults are overly self-protective and may reject social media or m-learning. This can result in them being marginalized. A female participant said:

"I used to think that there are so many bad guys on the Internet, and I was unwilling to contact people online. But I discovered that my friends in real life use WeChat to chat and organize activities. I realized that if I don't try to use WeChat, I will miss many activities and lose contact with my friends."

\section{Discussion}

Based on the existing TAM model, this study proposed a model that predicted behavioral intentions for the adoption of social media for learning among older adults in China. A mixed-methods approach was used in this study, in which the quantitative study phase confirmed the accuracy of the proposed model, and the qualitative study phase deepened the understanding of the quantitative results. Technology anxiety (TA), self-efficacy (SE), previous experience (PE), subjective norm (SN), and facilitating conditions (FC) were all found to have a significant influence on behavioral intention. Therefore, based on the above research results, the following recommendations are proposed for researchers, educators, and practitioners who want to promote the use of mobile social media for learning.

First, from the perspective of individual and organizational factors, colleges or teachers should select appropriate social media applications and establish relevant courses or training for them. It is important that they select social media applications that older adults are already familiar with. In China, WeChat is a good choice for Chinese senior citizens, given its widespread use in that demographic. Many older adults may have PE of using WeChat and their familiarity with the application could ease their TA. Table 9 lists three 


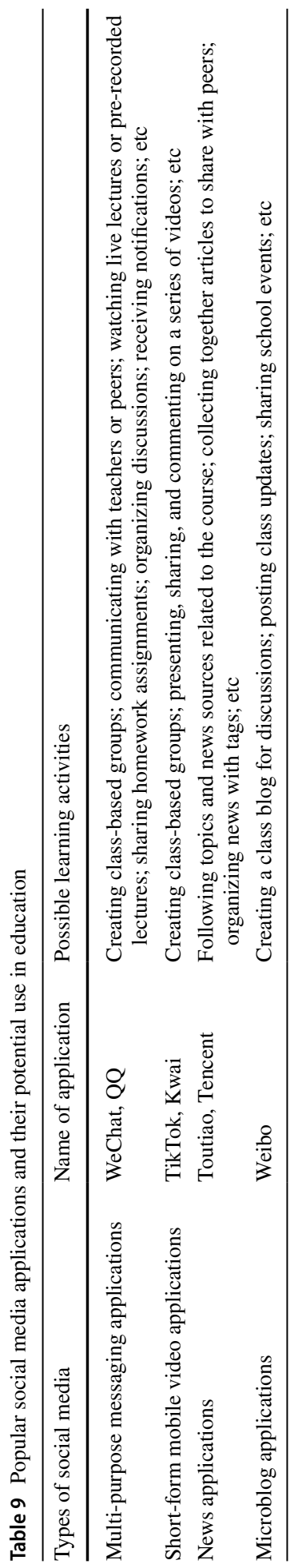


categories of social media applications that older adults are generally familiar with, as well as possible ways to use social media in senior citizen education. Colleges should also offer courses that are more relevant to the needs of senior citizens. There are two major issues that should be considered when establishing courses or trainings. The first aspect is that the course should focus on ICT skills, including the basic use of a mobile phone and the use of common social media platforms for learning. Such content could reduce students' TA and improve their SE. Teacher training is another possible avenue for constructive intervention. According to the qualitative data, SN has a positive influence on PU and PEU. If teachers use social media for teaching or encourage the students to use it, then older adults will be more inclined to use it. The second aspect is that learning materials related to information literacy should be included. For example, teachers could introduce the advantages of mobile social media and information about identifying and preventing network fraud. As a

Fig. 2 WeChat official account of China Open University for the Aged (in Chinese)

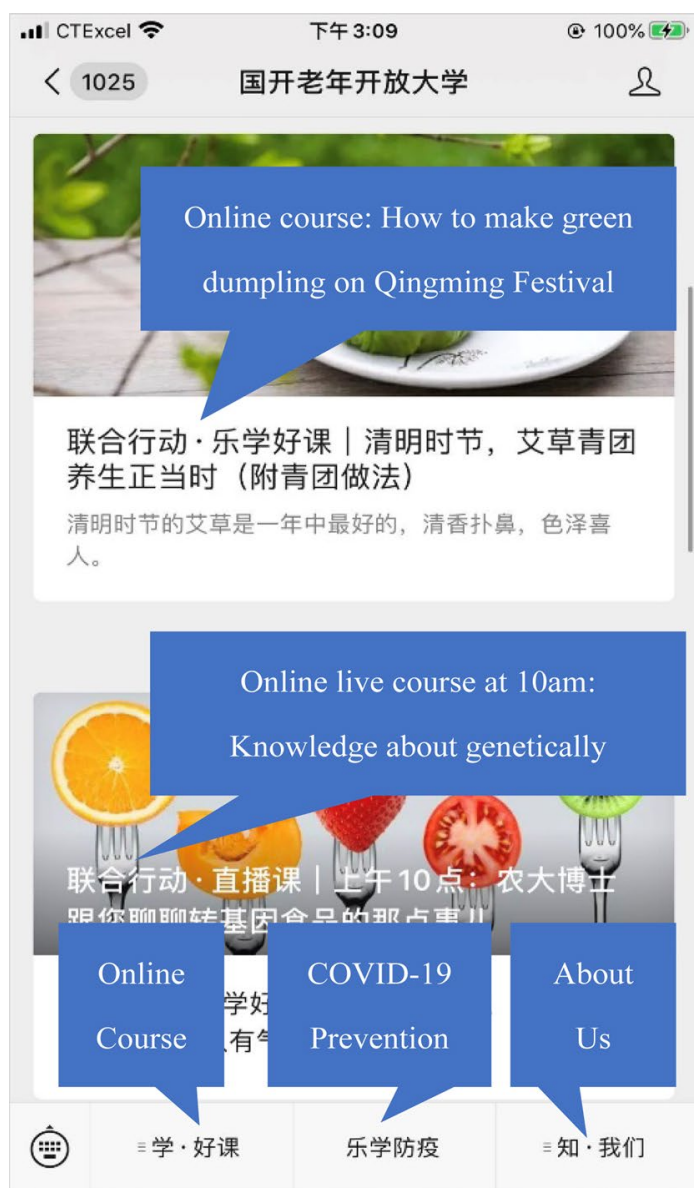


Fig. 3 WeChat mini-application of China Open University for the Aged (in Chinese)

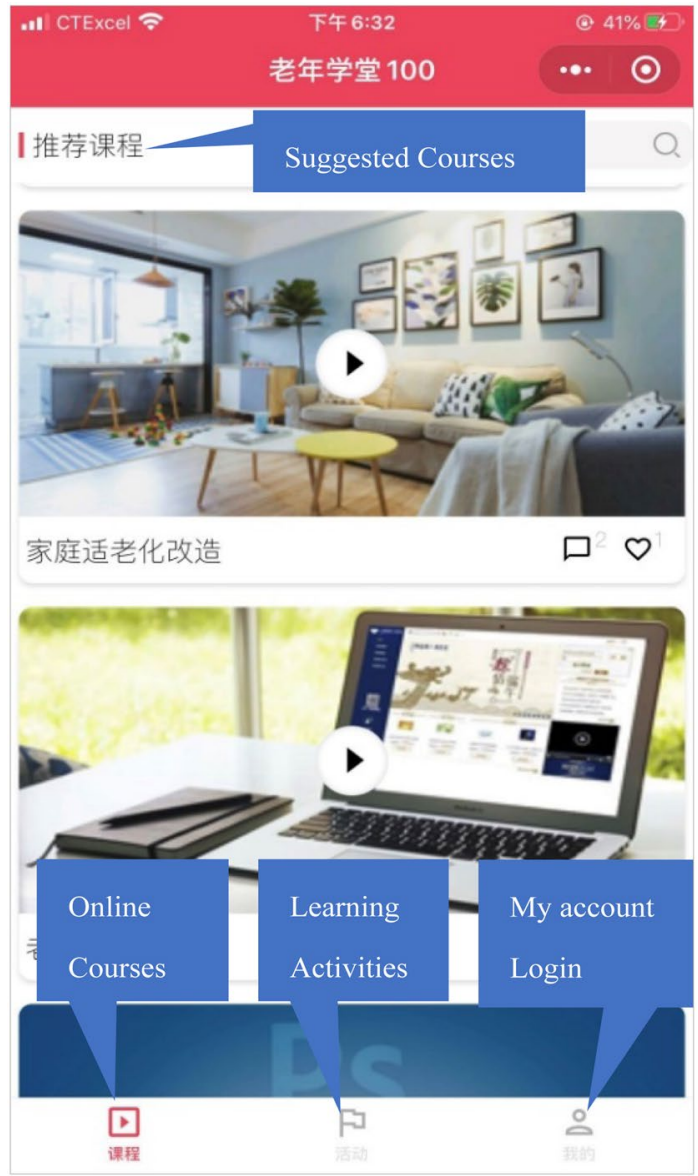

result, students' TA would be reduced and students' SE, SN, and adoption behavior would be improved through these courses.

Second, from the perspective of social factors, inexpensive network service and highquality learning support services are essential, as FC has a direct influence on PEU. For example, in order to address the elderly's concerns about Internet cost, senior citizen colleges should offer free wireless Internet. Older adults could choose an appropriate cell phone plan, such as an unlimited data plan or a family plan. There are two main types of learning support that should be offered. The first concerns learning materials. The qualitative data showed that most older Chinese adults are interested in inspirational articles, jokes, and politics. Teachers should consider integrating such materials into their courses. The second is learning support services, including tutoring and tech support for online learners. There are many ways to improve learning support services, such as creating official mobile social accounts, developing high-quality learning content, and establishing a robust online feedback system. WeChat official accounts and mini-applications (Graziani, 2019) built by the colleges have started to draw a lot of interest in China. Examples are 
shown in Figs. 2 and 3. Students can obtain useful notifications and learning materials pushed by the colleges and can leave a message for the instructor or communicate with them directly. Students' learning process data can be recorded, and then used by managers and teachers to analyze students' interests, learning behaviors, and habits. The teachers can then choose a suitable time and target content for the students through social media applications.

\section{Conclusions and limitations}

The elderly as a percentage of the world's population is increasing at a dramatic rate. The capacity of older adults to remain physically, mentally, and socially active is partly dependent on their continued participation in learning and education (Purdie \& Boulton-Lewis, 2003). Learning by mobile social media has become a trend among older people. However, despite the growing interest in social media research, there have been few studies on the adoption of mobile social media by older adults for learning. Using a mixed-methods approach, this study analyzed the factors influencing older adults' engagement in using mobile social media for learning, based on an extended TAM. The quantitative portion of this study closes the research gap by incorporating individual, social, and organizational factors into TAM. The qualitative portion of this study not only strengthened the explanatory power of the model but also deepened our understanding of the qualitative data. Most prior studies based on TAM have made use of quantitative methods only. We believe the mixed methods approach used in this study could enhance the explanatory power of future studies based on TAM. This study could also help researchers, educators, and practitioners better understand aspects of older adults' learning behavior in using social media, particularly mobile social media. Furthermore, the findings provide teachers with valuable information to enable them to promote the use of mobile social media by older people.

This study was conducted in the context of older Chinese adults, and while the findings could be applicable in other contexts, further research is needed to verify generalizability. Other limitations of this study should be considered when using these findings. First, the research sample size was relatively small considering the size of the elderly population in China. Second, besides the constructs discussed in this research, other factors may influence older adults' behavioral intentions. For example, Heerink et al. (2008) proved that the construct of perceived enjoyment has an important effect on older people's behavioral intention toward a conversational robot. Ma et al. (2016) found that self-satisfaction had a positive effect on older people's acceptance of smartphone technology. These issues should be considered in future research. Third, in the qualitative study phase, only teachers and students were invited for interviews. Managers and relevant practitioners should also be considered in future research. This research should be considered as a preliminary study focusing on the adoption of mobile social media for learning among older Chinese adults. Researchers, managers, and teachers should push for the utilization of mobile social media to expand learning opportunities for older adults.

\section{Appendix}

See Table 10. 


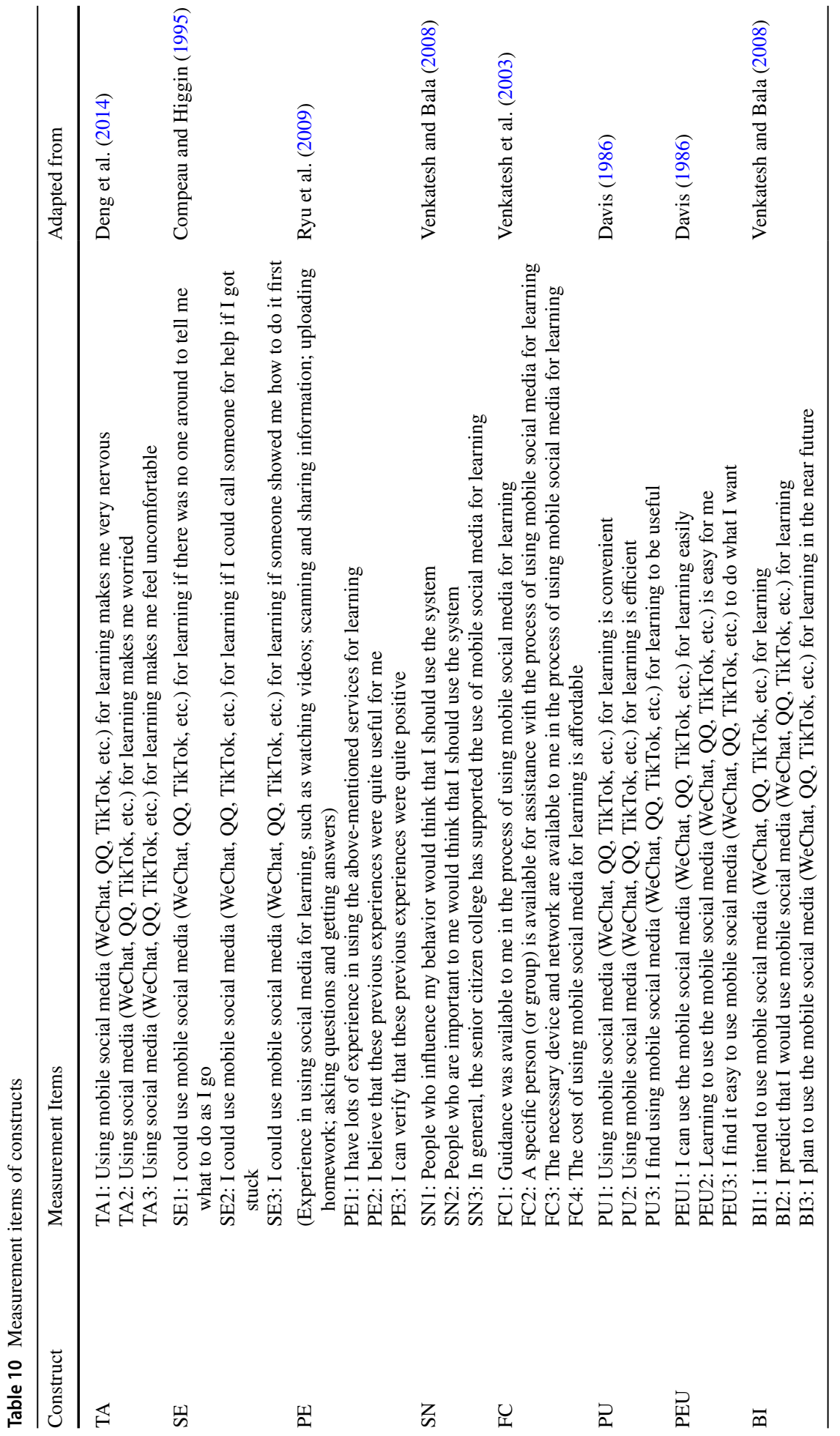


Funding This study was funded by the National Social Science Foundation of China "Design and Practice of Massive Open Online Courses (MOOCs) for the Elderly" (NO: CCA170258).

\section{Declarations}

Conflict of interest The authors declare that they have no conflict of interest.

Research involving human participants and/or animals This article does not contain any studies with human participants or animals performed by any of the authors.

\section{References}

Althunibat, A. (2015). Determining the factors influencing students' intention to use m-learning in Jordan higher education. Computers in Human Behavior, 52, 65-71.

Anderson, J. C., \& Gerbing, D. W. (1988). Structural equation modeling in practice: A review and recommended two-step approach. Psychological Bulletin, 103(3), 411-423.

Bandura, A. (1988). Self-efficacy conception of anxiety. Anxiety Research, 1(2), 77-98.

Byrne, B. M. (2016). Structural equation modeling with Amos: Basic concepts, applications, and programming. Routledge.

Chen, K., \& Chan, A. H. S. (2011). A review of technology acceptance by older adults. Gerontechnology, $10(1), 1-12$.

Chen, K., \& Chan, A. H. S. (2014). Gerontechnology acceptance by elderly Hong Kong Chinese: A senior technology acceptance model (STAM). Ergonomics, 57(5), 635-652.

China Youth Daily. (2016). About 60\% older adults worry about the pension after retirement. Retrieved January 01, 2020, from http://zqb.cyol.com/html/2016-03/10/nw.D110000zgqnb_20160310_1-T03. $\mathrm{htm}$ (in Chinese)

Chou, W. H., Lai, Y. T., \& Liu, K. H. (2013). User requirements of social media for the elderly: A case study in Taiwan. Behaviour \& Information Technology, 32(9), 920-937.

Chow, M., Herold, D. K., Choo, T. M., \& Chan, K. (2012). Extending the technology acceptance model to explore the intention to use Second Life for enhancing healthcare education. Computers \& Education, 59(4), 1136-1144.

Compeau, D. R., \& Higgins, C. A. (1995). Computer self-efficacy: Development of a measure and initial test. MIS Quarterly, 19(2), 189.

Creswell, J. W. (2003). Research design: Qualitative, quantitative, and mixed methods approaches. SAGE.

Creswell, J. W., \& Clark, V. L. P. (2007). Designing and conducting mixed methods research. Sage.

Davis, F. D. (1986). A technology acceptance model for empirically testing new end-user information systems: Theory and results. Doctoral dissertation, Massachusetts Institute of Technology. Retrieved December 10, 2019, from http://hdl.handle.net/1721.1/15192

Deng, Z., Mo, X., \& Liu, S. (2014). Comparison of the middle-aged and older users' adoption of mobile health services in China. International Journal of Medical Informatics, 83(3), 210-224.

Dyck, J. L., Gee, N. R., \& Smither, J.A.-A. (1998). The changing construct of computer anxiety for younger and older adults. Computers in Human Behavior, 14(1), 61-77.

$\mathrm{Fu}, \mathrm{M}$. (2019). Exploration and Reflection on the Integration of mobile learning and Social network for the elderly. Journal of Anhui Agricultural University (social Science Edition), 01, 110-113. (in Chinese).

Findsen, B., \& Formosa, M. (2012). Lifelong learning in later life a handbook on older adult learning. Sense Publ.

Fornell, C., \& Larcker, D. F. (1981). Evaluating structural equation models with unobservable variables and measurement error. Journal of Marketing Research, 18(1), 39.

General Office of the State Council. (2016). Education development plan for the elderly (2016-2020). Retrieved November 10, 2019, from http://www.gov.cn/zhengce/content/2016-10/19/content_ 5121344.htm (in Chinese)

Gikas, J., \& Grant, M. M. (2013). Mobile computing devices in higher education: Student perspectives on learning with cellphones, smartphones \& social media. The Internet and Higher Education, 19, 18-26.

Goswami, S., Köbler, F., Leimeister, J. M. \& Krcmar, H. (2010). Using online social networking to enhance social connectedness and social support for the elderly. Paper presented at the $31 \mathrm{st}$ 
International Conference on Information Systems. Retrieved November 11, 2019, from https:// www.alexandria.unisg.ch/220640/1/JML_234.pdf

Graziani, T. (2019, December 5). What are WeChat mini-programs? A simple introduction. Retrieved November 10, 2019, from https://walkthechat.com/wechat-mini-programs-simple-introduction/

Hair, J. F., Black, W. C., Babin, B. J., Anderson, R. E., \& Tatham, R. L. (2009). Multivariate data analysis (7th ed.). Pearson Prentice Hall.

Hao, S., Dennen, V. P., \& Mei, L. (2017). Influential factors for mobile learning acceptance among Chinese users. Educational Technology Research and Development, 65(1), 101-123.

Heerink, M., Kröse, B., Wielinga, B., \& Evers, V. (2008, March). Enjoyment intention to use and actual use of a conversational robot by elderly people. Paper presented at the 3rd International Conference on Human Robot Interaction

Kaplan, A. M., \& Haenlein, M. (2010). Users of the world, unite! The challenges and opportunities of social media. Business Horizons, 53(1), 59-68.

Kline, R. B. (2005). Principles and practice of structural equation modeling (2nd ed.). The Guilford Press.

Lee, D. Y., \& Lehto, M. R. (2013). User acceptance of YouTube for procedural learning: An extension of the Technology Acceptance Model. Computers \& Education, 61, 193-208.

Leen, E. A., \& Lang, F. R. (2013). Motivation of computer based learning across adulthood. Computers in Human Behavior, 29(3), 975-983.

Liu, Y., Zheng, Z., Rao, K., \& Wang, S. (2018). Annual report on elderly health in China 2018. Social Sciences Academic Press. (in Chinese).

$\mathrm{Lu}, \mathrm{L}$. (2012). Attitudes towards aging and older people's intentions to continue working: A Taiwanese study. Career Development International, 17(1), 83-98.

Ma, Q., Chan, A. H., \& Chen, K. (2016). Personal and other factors affecting acceptance of smartphone technology by older Chinese adults. Applied Ergonomics, 54, 62-71.

Mallenius, S., Rossi, M., \& Tuunainen, V.K. (2007). Factors affecting the adoption and use of mobile devices and services by elderly people-results from a pilot study. Paper presented at the 6th Annual Global Mobility Roundtable Conference.

National Bureau of Statistics of the People's Republic of China (2010). Tabulation on the 2010 population census of the people's republic of China. Retrieved January 12, 2020, from http://www.stats. gov.cn/tjsj/pcsj/rkpc/6rp/indexch.htm (in Chinese)

Nunnally, J. C., \& Bernstein, I. H. (1994). Psychometric theory. McGraw-Hill.

Park, S. Y., Nam, M. W., \& Cha, S. B. (2012). University students' behavioral intention to use mobile learning: Evaluating the technology acceptance model. British Journal of Educational Technology, 43(4), 592-605.

Purdie, N., \& Boulton-Lewis, G. (2003). The learning needs of older adults. Educational Gerontology, 29(2), 129-149.

Razavi, S. A., Shahrabi, A., \& Siamian, H. (2017). The relationship between research anxiety and selfefficacy. Materia Sociomedica, 29(4), 247-250.

Ruona, W. E. A. (2005). Analyzing qualitative data. In R. A. Swanson \& E. F. Holton (Eds.), Research in organizations: Foundations and methods of inquiry (pp. 223-263). Berrett-Koehler.

Ryu, M. H., Kim, S., \& Lee, E. (2009). Understanding the factors affecting online elderly user's participation in video UCC services. Computers in Human Behavior, 25(3), 619-632.

Saadé, R. G., \& Kira, D. (2009). Computer anxiety in e-learning: The effect of computer self-efficacy. Journal of Information Technology Education: Research, 8(1), 177-191.

Salili, F., Chiu, C., \& Lai, S. (2001). The influence of culture and context on students' motivational orientation and performance. In F. Salili, G. Ghiu, \& Y. Hong (Eds.), Student motivation: The Culture and context of learning (pp. 221-247). Kluwer Academic/Plenumm.

Scherer, R., Siddiq, F., \& Tondeur, J. (2019). The technology acceptance model (TAM): A meta-analytic structural equation modeling approach to explaining teachers' adoption of digital technology in education. Computers \& Education, 128, 13-35.

Steele, R., Lo, A., Secombe, C., \& Wong, Y. K. (2009). Elderly persons' perception and acceptance of using wireless sensor networks to assist healthcare. International Journal of Medical Informatics, 78(12), 788-801.

Tencent Technology Company. (2018). There were over 61 million WeChat older users. Retrieved December 10, 2019, from https://tech.qq.com/a/20181016/013129.htm. (in Chinese)

Venkatesh, V., \& Bala, H. (2008). Technology acceptance model 3 and a research agenda on interventions. Decision Sciences, 39, 273-315. 
Venkatesh, V., \& Davis, F. D. (2000). A theoretical extension of the technology acceptance model: Four longitudinal field studies. Management Science, 46(2), 186-204.

Venkatesh, V., Morris, M. G., Davis, G. B., \& Davis, F. D. (2003). User acceptance of information technology: Toward a unified view. MIS Quarterly, 27(3), 425-478.

Wu, W. H., Wu, Y. C. J., Chen, C. Y., Kao, H. Y., Lin, C. H., \& Huang, S. H. (2012). Review of trends from mobile learning studies: A meta-analysis. Computers \& Education, 59(2), 817-827.

Qutoutiao. (2020). Report on the internet life of the elderly. Retrieved January 30, 2020, from https://new. qq.com/rain/a/20201023A03JRZ00. (in Chinese)

Yang, Y., \& Wang, X. (2019). Modeling the intention to use machine translation for student translators: An extension of Technology Acceptance Model. Computers \& Education, 133, 116-126.

Yang, Y., \& Ouyang, Z. (2018). A case study on the matching of college education supply and learning needs of the elderly. Vocational \& Technical Education Forum, 8, 93-100. (in Chinese).

Zhang, Y. (2019). Interaction among the elderly in the mobile social era. Young Journalists, 36, 52-53. (in Chinese).

Publisher's Note Springer Nature remains neutral with regard to jurisdictional claims in published maps and institutional affiliations.

Shu Zhao is Assistant Professor in the College of Educational in Shaanxi Normal University. Her main research interests include learning technologies, mobile learning.

Kinshuk is Professor in the College of Information in University of North Texas. His research interests include learning analytics, learning technologies, cognitive profiling and interactive technologies.

Ying Yao is Director of the Academic Affairs Office of Weiyang Vocational Education Center. Her research interests include older adults course design and practice.

Nan Ya is a postgraduate student at the School of Distance Education in Shaanxi Normal University. Her main research interest is online learning for the elderly.

\title{
Authors and Affiliations
}

\author{
Shu Zhao ${ }^{1}$ (D) $\mathrm{Kinshuk}^{2} \cdot \mathrm{Ying} \mathrm{Yao}^{3} \cdot \mathrm{Nan} \mathrm{Ya}^{4}$ \\ Kinshuk \\ kinshuk@unt.edu \\ Ying Yao \\ yaoying1016@163.com \\ Nan Ya \\ 904234766@qq.com
}

1 College of Education, Shaanxi Normal University, No.199, South Chang'an Road, Yanta District, Xi' an 710062, People's Republic of China

2 College of Information, University of North Texas, 3940 N. Elm St, Denton, TX 76207, USA

3 Weiyang Vocational Education Center, Zhuhong Road, Weiyang District, Xi'an 710016, People's Republic of China

4 College of Distance Education, Shaanxi Normal University, No.199, South Chang'an Road, Yanta District, Xi' an 710062, People's Republic of China 